\title{
El discurso del profesor de inglés universitario como instancia de develación de su mundo cognitivo'
}

\author{
The University English Teacher's Discourse as an \\ Unraveling Instance of his Cognitive World
}

Claudio Díaz Larenas 2

Astrid Guerra Azócar ${ }^{3}$

\section{Resumen}

Este artículo aborda las creencias lingüístico-pedagógicas que se desprenden del discurso de un grupo de 30 profesores de inglés universitarios sobre su rol en el proceso de enseñanza y aprendizaje del inglés en la universidad. Con una metodología cualitativa, se utilizan dos entrevistas semi-estructuradas y diarios autobiográficos que aportan datos que son analizados y triangulados con la técnica del análisis de contenido estructural y el software ATLASTI. Se estructuran 17 categorías con sus correspondientes subcategorías que desmenuzan en profundidad el rol del docente en la enseñanza y aprendizaje del inglés.

\section{Palabras clave}

Inglés, creencias, profesores, entrevistas, universidad.

Abstract

This paper approaches the linguistic and pedagogical beliefs that underlie a group of 30 university teachers' discourse about their role in the English teaching and learning process in college. Through a qualitative methodology, two semi-structured interviews and autobiographical journals are used to gather the data that is analyzed and triangulated by the structural content analysis technique and the ATLASTI software. Seventeen categories and their corresponding subcategories are structured to unravel profoundly the teachers' role in the English teaching and learning.

Keywords

English, beliefs, teachers, interviews, university.

Artículo recibido el 26 Junio de 2011 y aprobado el 30 Marzo de 2012

1 Este artículo es parte del proyecto FONDECYT 1120247 titulado Investigación del Conocimiento Profesional, las Creencias Implícitas y el Desempeño en Aula de Estudiantes de Pedagogía en Inglés como Estrategia de Generación de Indicadores de Monitoreo de su Proceso Formativo y del proyecto FONDECYT 1085313 denominado El Sistema de Cognición Docente, las Actuaciones Pedagógicas del Profesor de Inglés Universitario y su Impacto en la Enseñanza-Aprendizaje del Idioma.

2 Doctor en Educación. Magíster en Lingüística. Profesor Asociado de la Universidad de Concepción. Concepción, Chile claudiodiaz@udec.cl

3 Magíster en Educación. Profesora de la Universidad Católica de la Santísima Concepción. Concepción, Chile aguerra@ucsc.cl 


\section{Introducción}

El proceso de enseñanza de un idioma requiere el reconocimiento de una serie de aspectos relacionados directa e indirectamente con él. En este contexto, un ámbito que permitiría abordar esta tarea es el de la cognición del profesor universitario, respecto tanto a la enseñanza del idioma como a su propia práctica pedagógica. De ahí la importancia de explorar en el campo de las creencias implícitas, ya que ellas inciden directamente en la práctica pedagógica y en el posible éxito o fracaso del proceso de enseñanza y aprendizaje.

Durante el ejercicio profesional, los docentes se ven enfrentados diariamente a establecer juicios y tomar decisiones en variados ámbitos de su quehacer pedagógico. El concepto de creencias en este contexto comprende todos aquellos constructos mentales que provienen de fuentes tales como las experiencias personales, los prejuicios, los juicios, las ideas y las intenciones. Por otra parte, parece de suma importancia asociar la práctica pedagógica a la reflexión teórica permanente. En este mismo sentido la investigación, como eje de la práctica pedagógica en los programas de formación y actualización de maestros, es una manera eficaz y sencilla de encontrar espacios que posibiliten compartir experiencias y objetivos comunes, pues permite el reconocimiento del otro y la valoración de las experiencias como fuente constante de conocimiento y enriquecimiento. Si los docentes reflexionan respecto a sus creencias y prácticas pedagógicas, esto repercutirá en gran medida en cómo llevan a cabo la labor docente.

Existe bibliografía variada referente a las creencias pedagógicas sobre el proceso de enseñanza y aprendizaje de profesores a nivel general e internacional (Borg, 2003). Sin embargo, en la realidad chilena existe escasa investigación en esta área. En este mismo contexto, se han desarrollado estudios respecto a las creencias sobre el proceso de enseñanza y aprendizaje de estudiantes en formación (Blázquez y Tagle, 2010). Surge entonces la inquietud de aportar, desde la perspectiva de docentes chilenos y latinoamericanos como formadores de profesionales, en búsqueda de la comprensión de las creencias, con el fin de favorecer y mejorar la práctica pedagógica. Este estudio aborda las creencias lingüístico-pedagógicas de un grupo de 30 profesores de inglés universitarios, sobre su propio rol en el proceso de enseñanza y aprendizaje en la educación superior.

\section{Marco teórico}

\section{La dimensión cognitiva del docente}

Los profesores tienen ciertas "concepciones" o formas de entender el proceso de enseñanza y aprendizaje. En este sentido, Stenberg (2011) señala que "los cambios trascendentales en la calidad de la enseñanza universitaria no ocurrirán si no hay cambios en la concepción que tienen los docentes universitarios sobre la enseñanza”. En este contexto, parece relevante conocer algunas definiciones del concepto "creencias". Borg define las creencias como "las formas personales en que un profesor entiende a los estudiantes, la naturaleza del aprendizaje, la sala de clases, el rol del profesor en el aula, los objetivos pedagógicos" (2003, 100). Kane, Sanretto y Heath, en cambio, definen las creencias como "entendimientos, premisas o proposiciones psicológicas sobre el mundo que se sienten como verdaderas" $(2002,178)$.

En tanto, Pintor y Vizcarro (2005) explican que las creencias varían en su intensidad y tipo, y a través del tiempo forman un sistema. La facilidad con que un profesor cambia sus creencias está relacionada con la intensidad de estas. Mientras más marcada la creencia, mayor es la resistencia al cambio. Para reforzar esta idea, varios autores plantean que las creencias de los profesores están arraigadas en sus experiencias personales y por tanto son altamente resistentes al cambio (Goodson y Numan, 2002; Tsui, 2003). En contraste, Burns y Richards (2009) plantean que los sistemas de creencias son estructuras mentales dinámicas, permeables y susceptibles al cambio, dependiendo de las experiencias.

El estudio de las creencias lingüístico-pedagógicas permite la explicitación de los marcos de referencia mediante los cuales los docentes perciben y procesan la información, analizan, dan sentido y orientan su actuación pedagógica. Díaz, Martínez, 
Roa y Sanhueza (2010) señalan que estudiar las creencias de los docentes implica explorar el lado oculto de la enseñanza. Las creencias están compuestas por conjuntos más o menos integrados y consistentes de ideas que se construyen a partir de las experiencias cotidianas. Para González, Río y Rosales (2001), las creencias son versiones incompletas y simplificadas de la realidad, que si bien permanecen inaccesibles a la conciencia, tienen algún nivel de organización interna, estructuración y sistematicidad. Freeman (2002) defiende la importancia de reflexionar acerca de las creencias ya que esto puede traer consigo una serie de ventajas, tales como: llevar al plano consciente el pensamiento que está detrás de las acciones; los profesores pueden elegir enseñar en forma distinta de cómo aprendieron; pueden ayudarle al profesor a expandir sus técnicas y prácticas; pueden confirmar lo positivo que los docentes hacen dentro del aula o hacerlos repensar acerca de sus prácticas pedagógicas.

$\mathrm{Al}$ revisar bibliografía relacionada con las diferentes concepciones de "creencias", se puede identificar algunas características comunes. Levin y $\mathrm{He}$ (2008) mencionan algunas de estas características:

- El sistema de creencias tiene una función adaptativa que ayuda a las personas a definir y comprender el mundo y a ello/as mismo/as.

- Las estructuras paralelas se forman tempranamente y persisten frente a la contradicción causada por el tiempo, la razón, la escolaridad o la experiencia.

- Las personas desarrollan un sistema de creencias que alberga todas las creencias adquiridas mediante el proceso de transmisión cultural.

- El conocimiento y las creencias están intrínsecamente relacionados; sin embargo, la naturaleza afectiva, evaluativa y episódica de las creencias hacen que ellas se conviertan en un filtro mediante el cual se interpretan nuevos fenómenos.

- Las creencias epistemológicas tienen un rol fundamental en la interpretación del conocimiento y monitoreo cognitivo.
- Las creencias se priorizan, según las conexioneso relaciones con otras creencias u otras estructuras cognitivas y afectivas.

- El cambio de las creencias durante la adultez es un fenómeno poco frecuente.

- Las creencias son instrumentales en la definición de tareas y la selección de herramientas cognitivas con las cuales interpretar, planificar y tomar decisiones con respecto a las tareas; por lo tanto, las creencias tienen un rol fundamental en la definición de un comportamiento y la organización del conocimiento y la información.

Es innegable la importancia de las creencias en la enseñanza en general; sin embargo, no se puede aislar la relación que existe entre estas creencias y las prácticas pedagógicas. En el estudio realizado por Tudor (2001) se plantea la importancia de investigar acerca de las creencias de los profesores universitarios como una forma de enfatizar el importante rol que juegan estas en la práctica docente así como la relación existente entre ellas. Brown (2001, p. 19) aduce que "los profesores debieran ser tratados como aprendices activos que construyen sus propios entendimientos". Otra concepción que respalda esta idea es aquella que visualiza a los humanos como agentes que interactúan con un propósito en su entorno, aprenden de sus acciones y usan este aprendizaje para planear futuras acciones (Levin, 2001). En la práctica profesional, el conocimiento es tácito en general, se desarrolla con la práctica y raramente se hace explícito. De aquí se desprenden dos teorías. Por un lado, las teorías expuestas, que contienen el conocimiento que una persona reproduce cuando se le solicita que justifique sus acciones; por otro, las teorías en uso, referidas a las estructuras del conocimiento que guían las acciones. No siempre hay una concordancia entre ambas y se debe tener en cuenta su implicancia en el significado que se atribuya a los informes verbales de los profesores.

Montecinos, Solís, Contreras y Rittershaussen (2009) indican que lograr que un profesor sienta la necesidad de mejorar su práctica, reflexione sobre ella y busque estrategias didácticas alternativas, es un buen camino de perfeccionamiento docente. Sin embargo, para que el cambio tenga un mayor efecto y 
sea permanente en el tiempo, se requiere que esta reflexión sea temprana, con el fin de renovar aquellos comportamientos y criterios arraigados, pero ineficaces desde el punto de vista pedagógico.

Por otro lado, parece interesante citar a Pintor y Vizcarro, quienes plantean que "existen amplias posibilidades de cambio, desarrollo y enriquecimiento e incluso cambio conceptual hacia posiciones que epistemológicamente se pueden considerar más complejas y ricas en su proyección docente, en una línea más flexible y multiperspectivista" (2005, 625). En esta misma línea, Brown (2001) plantea la relevancia de investigar sobre el pensamiento y toma de decisiones de los profesores, la naturaleza y contenido de su pensamiento, la manera en que el pensamiento se ve influenciado por el contexto organizativo y curricular en el que los profesores trabajen, $\mathrm{y}$ la forma en que los pensamientos de los profesores se relacionan con su conducta en clase y $\mathrm{y}$, en último término, con los pensamientos y conductas de los alumnos. Todo lo anterior permitiría superar el nivel de comprensión de los procesos instructivos que ocurren dentro de la sala de clases y la consecuente mejora en la práctica del docente.

\section{El proceso de enseñanza y aprendizaje del inglés}

En el contexto de la didáctica de las lenguas extranjeras se abordan distintos enfoques: un enfoque didáctico tradicional y un enfoque didáctico comunicativo. El enfoque tradicional enfatiza el dominio de las estructuras fonológicas, léxicas y gramaticales de la lengua y concentra esfuerzos en prevenir errores por parte de los estudiantes. Se utiliza la mímica, la memorización y los diálogos para lograr un aprendizaje efectivo. El docente debe ser hábil fundamentalmente en las estructuras lingüísticas, ya que todo el material y las actividades de enseñanza son controlados cuidadosamente (Burns y Richards, 2009; Brown, 2001).

En el enfoque comunicativo, el aprendizaje de una lengua es visto como adquisición y no como hábito de formación; cada estudiante es también responsable de su auto-aprendizaje. Las estructuras léxicas, fonológicas y gramaticales son enseñadas mediante situaciones comunicativas que permiten al estudiante desarrollar su saber según su ritmo y desarrollo de la clase. El vocabulario tiene gran importancia; los errores son vistos como inevitables y contribuyen al aprendizaje. La didáctica comunicativa centra su atención en la enseñanza y el aprendizaje, en la comunicación como un acto creativo, consciente y espontáneo, que se produce entre dos o más sujetos activos, donde la forma lingüística y el significado forman una unidad dialéctica indisoluble. La categoría que más resalta es la función comunicativa, es decir, la manifestación de las necesidades de los sujetos interactuantes para emitir opiniones y solicitar y/o proporcionar información. La característica esencial de la didáctica de la lengua inglesa es que su objeto de estudio específico le viene dado por la interrelación de las diferentes variables presentes en el proceso de enseñanza y aprendizaje. "El proceso de transposición general se efectúa dialécticamente, de modo que debe existir una conjunción coherente de principios, objetivos, contenidos, métodos y evaluación, corrigiéndose unos a otros, y proporcionando pautas de reflexión y/o actuación de modo integrado y retroactivo" (Tudor, 2001, 78).

\section{Metodología de investigación}

\section{Diseño de investigación}

Este es un estudio no experimental de tipo transeccional, modalidad estudio de caso analítico-interpretativo (Bisquerra, 2009; Canales, 2006), puesto que indaga en las creencias lingüístico-pedagógicas de 30 docentes universitarios de inglés en dos universidades chilenas, respecto a su propio rol y funciones en el proceso de enseñanza y aprendizaje del inglés en la educación superior. En un estudio de caso, los datos y análisis son examinados profunda y detalladamente, y son relevantes en la medida que el lector los contextualice a su propia realidad psicopedagógica.

\section{Informantes}

Los 30 participantes de esta investigación conforman una muestra no probabilística de tipo intencionada (Corbetta, 2007), donde los sujetos son seleccionados uno a uno por las características específicas que ellos ofrecen: profesores universitarios que 
enseñan inglés en universidades nacionales, con más de cinco años de experiencia y un promedio de 45 años de edad.

\section{Pregunta de investigación}

¿Qué creencias lingüístico-pedagógicas conforman la dimensión cognitiva de un grupo de 30 profesores de inglés universitarios sobre su propio rol en la enseñanza y aprendizaje del inglés en la educación superior?

\section{Supuesto de la investigación}

Las creencias lingüístico-pedagógicas influyen en la práctica docente. Durante el proceso de enseñanza y aprendizaje, los profesores deben tomar una serie de decisiones, que son guiadas por sus creencias lingüístico-pedagógicas y definen su actuación en el aula. El hecho de traer al plano consciente las creencias implícitas que están detrás de las acciones ayuda a que los profesores puedan mantener aquellas prácticas pedagógicas que les resultan positivas y puedan elegir enseñar en forma distinta de cómo aprendieron o replantear aquellas prácticas que no resultan exitosas.

\section{Técnicas de generación de los datos}

- Entrevista semi-estructurada, que refiere a un modelo especializado de interacción verbal, iniciado para comprender el fenómeno de las creencias lingüístico-pedagógicas sobre el rol docente de los informantes. Las dimensiones que forman parte de la pauta de entrevista son: principios teóricos de la enseñanza del inglés; enfoques de enseñanza; el docente: rol y funciones; el docente de inglés como un profesional de la educación; el rol del discente; los estilos de aprendizaje; la relación entre objetivos, contenidos, métodos y actividades; el contexto: recursos didácticos, materiales, TIC y la evaluación de los aprendizajes. Este artículo centra su atención en uno de los actores relevantes en la innovación pedagógica: el docente, su rol y funciones en el proceso didáctico.
- Entrevista de autorreflexión, en la que se le solicita a los participantes elaborar una línea de tiempo con las experiencias que consideran más relevantes de su ejercicio profesional para luego explicar el por qué.

- Diario autobiográfico, registro en el cual el informante escribe acerca de su experiencia de enseñanza en el aula, tan regularmente como sea posible por un período de seis meses, para luego analizar los patrones y eventos registrados. El valor de los diarios autobiográficos, como procedimiento, permite averiguar qué es lo que piensan los profesores. En la presente investigación, el diario autobiográfico se utiliza para registrar las perspectivas e impresiones en torno a la vida cotidiana del docente en la universidad, es decir, su experiencia diaria (Sevillano, Pascual y Bartolomé, 2007).

\section{Procedimiento de análisis de los datos}

Luego de validar los instrumentos, se recolectó la información obtenida de los diarios autobiográficos, las entrevistas semi-estructuradas y de autorreflexión, y se realizó el análisis de los datos. El análisis de datos es la representación o reconstrucción del fenómeno social. De esta manera se crean consideraciones de la vida social y se construyen versiones de los mundos sociales y sus actores. Se realizó un análisis de contenido estructural inicial para después someter los datos al software de análisis cualitativo ATLASTI, que permite buscar la coherencia y el sentido explícito e implícito en los datos, mediante la dialéctica entre la comprensión del texto y la interpretación de las partes. Para Sandín (2005) y Cerda (2007) la interpretación hermenéutica resalta la condición de la experiencialidad humana, la acción del hombre que se expresa en el texto, producto de su acción en el mundo. El análisis de los datos sigue la siguiente trayectoria: transcripción, segmentación, codificación, categorización inicial, búsqueda sistemática de las propiedades de las categorías, integración de las categorías y finalmente 
la búsqueda de relaciones entre las categorías para establecer las sub-categorías.

Estas categorías y subcategorías son sometidas a la triangulación por investigador y por método investigativo, hasta que se produce la saturación de los datos que garantiza la confiabilidad en los estudios cualitativos.

\section{Análisis y discusión de los datos}

En esta sección se aborda la dimensión que se detalla a continuación:

\section{Dimensión: el docente de inglés universitario en el proceso de enseñanza y aprendizaje del idioma}

Esta dimensión comprende el rol del docente en el proceso de enseñanza y aprendizaje del idioma. Se establecen 16 categorías, la mayoría de las cuales se divide en subcategorías que emergen del discurso de los informantes (Wilkinson y Birmingham, 2003) ya sea en la entrevista semi-estructurada, de autorreflexión o en el diario autobiográfico (ver tabla 1).

Tabla 1: Categorías y subcategorías para el rol del docente en el proceso de enseñanza y aprendizaje del idioma

\begin{tabular}{|c|c|c|}
\hline Categorías & Subcategorías & $\begin{array}{l}\text { Técnica de generación de informa- } \\
\text { ción }\end{array}$ \\
\hline $\begin{array}{l}\text { 1. Etapas claves en la formación del do- } \\
\text { cente de inglés }\end{array}$ & $\begin{array}{l}\text { - Estudio de pregrado } \\
\text { - Experiencia laboral } \\
\text { - Estudio de postgrado }\end{array}$ & Entrevista de autorreflexión \\
\hline $\begin{array}{l}\text { 2. Fuentes de creencias sobre la ense- } \\
\text { ñanza del inglés }\end{array}$ & $\begin{array}{l}\text { - Estudios universitarios } \\
\text { - Experiencia } \\
\text { - Perfeccionamiento } \\
\text { - Literatura }\end{array}$ & Diario autobiográfico \\
\hline 4. Fortalezas como profesor & $\begin{array}{l}\text { - Relación con estudiantes } \\
\text { - Preparación de clases } \\
\text { - Características personales } \\
\text { - Dominio del idioma } \\
\text { - Manejo de TIC } \\
\text { - Dominio de los contenidos }\end{array}$ & Diario autobiográfico \\
\hline 5. Debilidades como profesor & $\begin{array}{l}\text { - Relación con estudiantes } \\
\text { - Características personales } \\
\text { - Uso de TIC } \\
\text { - Trabajo en equipo } \\
\text { - Perfeccionamiento } \\
\text { - Manejo del tiempo }\end{array}$ & Diario autobiográfico \\
\hline $\begin{array}{l}\text { 6. Características de un buen profesor } \\
\text { de inglés }\end{array}$ & $\begin{array}{l}\text { - Dominio del idioma } \\
\text { - Proveedor de un ambiente propicio para el aprendizaje } \\
\text { - Difusor de la cultura extranjera } \\
\text { - Planificación de sus clases utilizando metodologías va- } \\
\text { riadas } \\
\text { - Características personales }\end{array}$ & Entrevista semiestructurada \\
\hline 7. Rol del profesor de inglés & $\begin{array}{l}\text { - Facilitador } \\
\text { - Proveedor de materiales y recursos didácticos } \\
\text { - Persona que controla, dirige y monitorea } \\
\text { - Combinación de roles en el aula } \\
\end{array}$ & $\begin{array}{l}\text { Entrevista semiestructurada } \\
\text { Diario autobiográfico }\end{array}$ \\
\hline $\begin{array}{l}\text { 8. Influencia del contexto social de los } \\
\text { estudiantes en el aprendizaje del idioma }\end{array}$ & -Contexto social de los estudiantes & Entrevista semiestructurada \\
\hline $\begin{array}{l}\text { 9. Funciones más frecuentes realizadas } \\
\text { por el profesor de inglés }\end{array}$ & $\begin{array}{l}\text { - Respuesta a interrogantes de los estudiantes } \\
\text { - Retroalimentación positiva } \\
\text { - Enseñanza de estrategias lingüísticas } \\
\text { - Demostración de actividades } \\
\text { - Monitoreo del trabajo del estudiante } \\
\text { - Manejo de curso }\end{array}$ & $\begin{array}{l}\text { Entrevista semiestructurada } \\
\text { Diario autobiográfico }\end{array}$ \\
\hline $\begin{array}{l}\text { 10. Estrategias de aprendizaje utilizadas } \\
\text { en las clases de inglés }\end{array}$ & $\begin{array}{l}\text { - Utilización de estrategias variadas } \\
\text { - Utilización de algunas estrategias } \\
\text { - Ausencia de uso de estrategias }\end{array}$ & $\begin{array}{l}\text { Diario autobiográfico } \\
\text { Entrevista semiestructurada }\end{array}$ \\
\hline
\end{tabular}




\begin{tabular}{|c|c|c|}
\hline $\begin{array}{l}\text { 11. Características de un profesional de } \\
\text { la educación }\end{array}$ & $\begin{array}{l}\text { - Formación disciplinar y pedagógica del profesor de inglés } \\
\text { - Aprendizaje continuo tanto en la disciplina como en el } \\
\text { ámbito pedagógico } \\
\text { - Compromiso educativo con los alumnos } \\
\text { - Compromiso educativo con la institución educativa } \\
\text { - Capacidad de reflexión y de producción de conocimiento }\end{array}$ & Entrevista semiestructurada \\
\hline $\begin{array}{l}\text { 12. Cambios sugeridos para los docen- } \\
\text { tes de inglés en Chile }\end{array}$ & $\begin{array}{l}\text { - Aspectos metodológicos } \\
\text { - Aspectos actitudinales } \\
\text { - Formación inicial docente } \\
\text { - Aspectos administrativos de la institución educacional }\end{array}$ & Entrevista semiestructurada \\
\hline 13. Tipo de perfeccionamiento sugerido & $\begin{array}{l}\text { - Áreas de interés del profesor } \\
\text { - Actualización en aspectos académicos } \\
\text { - Manejo del idioma } \\
\text { - Gestión de aula }\end{array}$ & Entrevista semiestructurada \\
\hline $\begin{array}{l}\text { 14. Aspectos reconfortantes de ser pro- } \\
\text { fesor }\end{array}$ & $\begin{array}{l}\text { - Logro de objetivos } \\
\text { - Interacción personal } \\
\text { - Lograr cambios en los estudiantes }\end{array}$ & $\begin{array}{l}\text { Entrevista semiestructurada } \\
\text { Diario autobiográfico } \\
\text { Entrevista de autorreflexión }\end{array}$ \\
\hline $\begin{array}{l}\text { 15. Aspectos menos reconfortantes de } \\
\text { ser profesor }\end{array}$ & $\begin{array}{l}\text { - Falta de logro de los estudiantes } \\
\text { - Aspectos administrativos } \\
\text { - Falta de motivación por parte de los estudiantes }\end{array}$ & $\begin{array}{l}\text { Entrevista semiestructurada } \\
\text { Diario autobiográfico } \\
\text { Entrevista de autorreflexión }\end{array}$ \\
\hline 16. Evaluación docente & - Grado de aprobación & Entrevista semiestructurada \\
\hline $\begin{array}{l}\text { 17. Sugerencia de formato de la evalua- } \\
\text { ción docente }\end{array}$ & $\begin{array}{l}\text { - Observación de un especialista } \\
\text { - Observación directa } \\
\text { - Participación de todos los agentes del ámbito educativo }\end{array}$ & Entrevista semiestructurada \\
\hline
\end{tabular}

En una primera categoría se analizan las etapas que los informantes consideran claves en su formación como docentes de inglés. Es interesante notar que los estudios de pregrado y el período de práctica profesional en la universidad son levemente calificados como claves en la formación de estos profesores. Una posible causa para esta percepción es que la mayoría de los informantes estudiaron con un plan de estudio que no contemplaba prácticas pedagógicas tempranas que les brindaran la oportunidad de tener contacto directo con todos los agentes involucrados en el proceso de enseñanza y aprendizaje o que les invitaran a reflexionar acerca de ellos. A diferencia de estas, la experiencia laboral es percibida como muy significativa tanto por la posibilidad de tener contacto directo con los estudiantes, como por los beneficios que aporta el estar en un contexto real de enseñanza y aprendizaje, donde se pueden aplicar distintas teorías y metodologías, lo que permite a su vez reflexionar acerca de aquellas que son apropiadas para ciertas realidades y aquellas que se deben adaptar o si es necesario innovar. En la tabla 2 se aprecian algunos fragmentos de la entrevista de autorreflexión que respaldan las subcategorías antes mencionadas.
Tabla 2: Etapas claves en la formación del docente de inglés

\begin{tabular}{|l|l|l|}
\hline Sujeto & Fragmento & $\begin{array}{l}\text { Técnica de genera- } \\
\text { ción de información }\end{array}$ \\
\hline 10 & $\begin{array}{l}\text { "Mi verdadera entrada al ám- } \\
\text { bito laboral fue en un institu- } \\
\text { to de idiomas, ahí me formé, } \\
\text { digamos, mis creencias y mi } \\
\text { formación profesional, diga- } \\
\text { mos, más que académico que } \\
\text { fue lo que me entregó la uni- } \\
\text { versidad." }\end{array}$ & $\begin{array}{l}\text { Entrevista de auto- } \\
\text { rreflexión }\end{array}$ \\
\hline 2 & $\begin{array}{l}\text { "Durante mi trayectoria... } \\
\text { aprendí manejo de grupo, que } \\
\text { es importante, aprendí algu- } \\
\text { nas técnicas de enseñanza } \\
\text { basadas en las habilidades } \\
\text { lingüísticas." }\end{array}$ & rreflexión de auto- \\
\hline
\end{tabular}

El gráfico 1 sintetiza las tendencias relativas a las opiniones de los informantes respecto a las etapas claves en la formación del docente de inglés.

Gráfico 1: Frecuencia de las etapas clave en la formación del docente de inglés

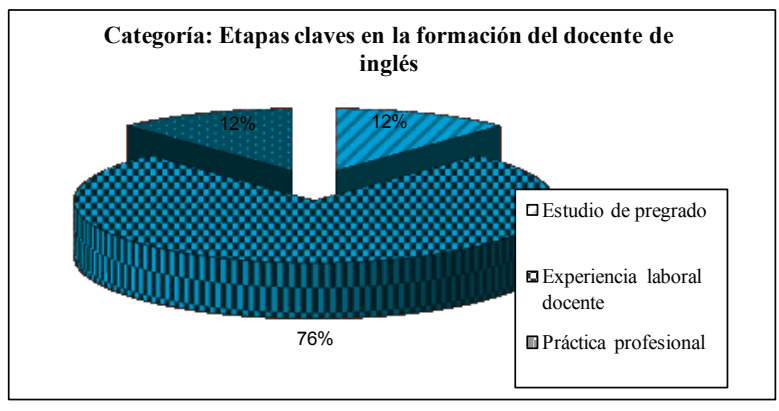

Con respecto a las fuentes de sus creencias sobre la enseñanza del inglés que tienen los profesores en 
estudio, la mayoría declara basarse en la literatura y en su propia experiencia laboral. Adicionalmente, un porcentaje importante reconoce que el perfeccionamiento ha influido en su concepto de enseñanza del inglés. Resulta interesante notar que un grupo muy reducido considera los estudios universitarios de pregrado como fuente para sus creencias. A continuación se aprecian algunos fragmentos de los diarios autobiográficos seleccionados.

Tabla 3: Orígenes de las creencias sobre la enseñanza del inglés

\begin{tabular}{|l|l|l|}
\hline Sujeto & Fragmento & $\begin{array}{l}\text { Técnica de genera- } \\
\text { ción de información }\end{array}$ \\
\hline $\begin{array}{l}\text { Sujeto } \\
5\end{array}$ & $\begin{array}{l}\text { "Mis fuentes son la literatura } \\
\text { especializada, el perfecciona- } \\
\text { miento, la experiencia laboral." }\end{array}$ & Diario autobiográfico \\
\hline
\end{tabular}

A continuación se grafican las principales fuentes de creencias sobre la enseñanza del inglés señaladas por los informantes.

Gráfico 2: Frecuencia de los orígenes de las creencias sobre la enseñanza del inglés

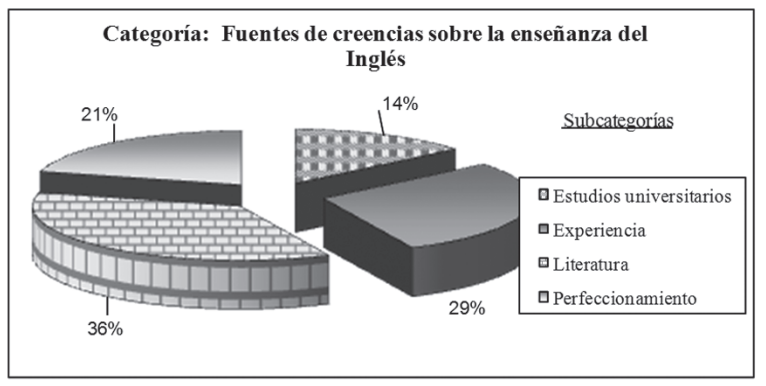

En la categoría fortalezas como profesor, los profesores concuerdan en considerar aspectos tales como: el manejo del idioma, el dominio de las TIC o del tema que enseñan. Asimismo, coinciden en mencionar la buena relación con sus estudiantes y la preparación de sus clases. Del mismo modo, señalan ciertas características personales que ellos poseen y que contribuyen tanto al ambiente que se genera en la clase como al aprendizaje efectivo. En la siguiente tabla se aprecian algunos fragmentos de sus diarios autobiográficos seleccionados para respaldar las subcategorías antes mencionadas.
Tabla 4: Fortalezas como profesor

\begin{tabular}{|l|l|l|}
\hline Sujeto & Fragmento & $\begin{array}{l}\text { Técnica de generación } \\
\text { de información }\end{array}$ \\
\hline 13 & $\begin{array}{l}\text { "Siempre respondo } \\
\text { con mucho entusiasmo } \\
\text { cuando los alumnos } \\
\text { requieren alguna infor- } \\
\text { mación." }\end{array}$ & Diario autobiográfico \\
\hline 15 & $\begin{array}{l}\text { "Una de mis fortalezas } \\
\text { es el manejo del idioma, } \\
\text { la tecnología y las estra- } \\
\text { tegias para la enseñan- } \\
\text { za del idioma inglés." }\end{array}$ & \\
\hline
\end{tabular}

El siguiente gráfico sintetiza las fortalezas que los informantes consideran como relevantes dentro de su labor docente.

Gráfico 3: Frecuencia de las fortalezas como profesor

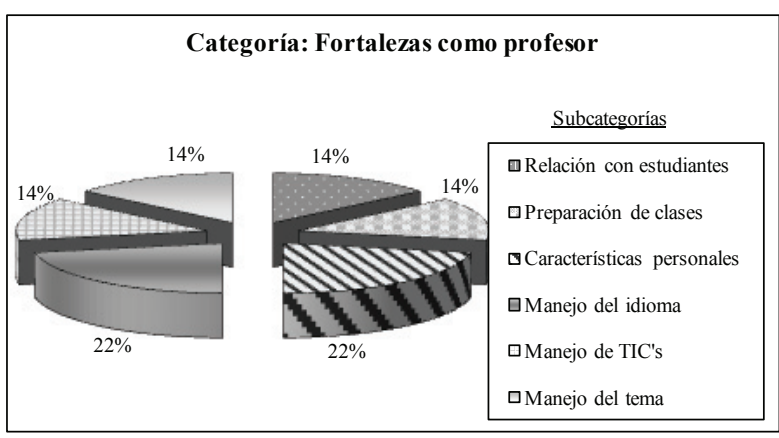

Algunas de las debilidades como profesor más aludidas por los informantes fueron sus características personales, tales como: la falta de sistematicidad, la impaciencia, la inseguridad en algunas áreas, entre otras. En un segundo plano se señalan la escasa relación con los estudiantes, el escaso manejo de las tecnologías de la información y comunicación (TIC), el insuficiente perfeccionamiento continuo, el deficiente manejo del tiempo y la falta de trabajo en equipo. A continuación se presentan algunos fragmentos de los diarios autobiográficos elegidos para respaldar las subcategorías antes mencionadas.

Tabla 5: Debilidades como profesor

\begin{tabular}{|l|l|l|}
\hline Sujeto & Fragmento & $\begin{array}{l}\text { Técnica de generación } \\
\text { de información }\end{array}$ \\
\hline 3 & $\begin{array}{l}\text { "Una de mis debilidades es } \\
\text { en algunas ocasiones la falta } \\
\text { de sistematicidad." }\end{array}$ & Diario autobiográfico \\
\hline 4 & $\begin{array}{l}\text { "Me falta ser constante en } \\
\text { las planificaciones de mis } \\
\text { clases." }\end{array}$ & Diario autobiográfico \\
\hline 12 & $\begin{array}{l}\text { "Una de mis debilidades es } \\
\text { querer lograr resultados en } \\
\text { el corto plazo." }\end{array}$ & Diario autobiográfico \\
\hline
\end{tabular}


El siguiente gráfico sintetiza las debilidades que los profesores declaran poseer.

Gráfico 4: Frecuencia de las debilidades como profesor

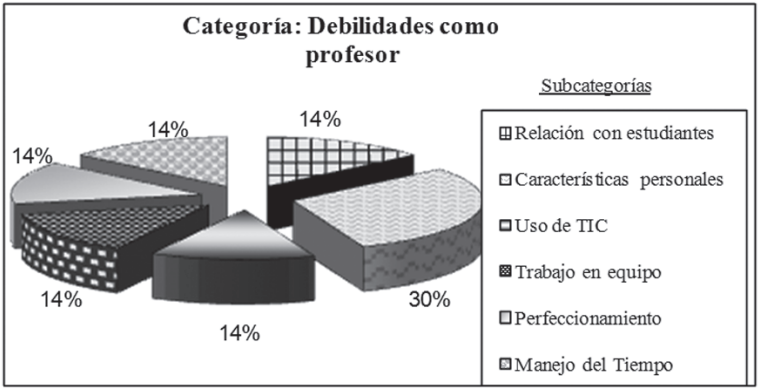

Respecto a la categoría características de un buen profesor de inglés, la mayoría de los sujetos entrevistados optó por aquellos rasgos que les permiten conformar un ambiente relajado y propicio para el aprendizaje. Se mencionaron aspectos tales como mantener una buena relación con los alumnos o preocuparse de los distintos ritmos de aprendizaje. La segunda mayoría se divide entre la importancia de sentirse seguro del dominio del idioma que se está enseñando y algunas características personales entre las que se pueden mencionar la utilización del humor y ser paciente y motivador. En un porcentaje inferior se menciona el ser capaz de planificar clases de acuerdo a nuevas metodologías y ser un difusor de la cultura extranjera. A continuación se aprecian algunos fragmentos seleccionados de las entrevistas semiestructuradas para respaldar las ideas mencionadas.

Tabla 6: Características de un buen profesor de inglés

\begin{tabular}{|l|l|l|}
\hline Sujeto & Fragmento & $\begin{array}{l}\text { Técnica de genera- } \\
\text { ción de información }\end{array}$ \\
\hline 12 & $\begin{array}{l}\text { "Un profesor tiene que ser una } \\
\text { persona espontánea, dinámi- } \\
\text { ca, entretenida, sobre todo en } \\
\text { idiomas; no puede cumplir el }\end{array}$ & $\begin{array}{l}\text { Entrevista semies- } \\
\text { tructurada. } \\
\text { rol de lecturer; debe ser una } \\
\text { persona que genera comuni- } \\
\text { cación, interacción, le da un } \\
\text { ambiente lúdico al aprendizaje } \\
\text { y también hace conexiones } \\
\text { culturales". }\end{array}$ \\
\hline
\end{tabular}

El siguiente gráfico sintetiza las tendencias de las opiniones de los informantes respecto a las características de un buen profesor de inglés.

Gráfico 5: Frecuencia de las características de un buen profesor de inglés

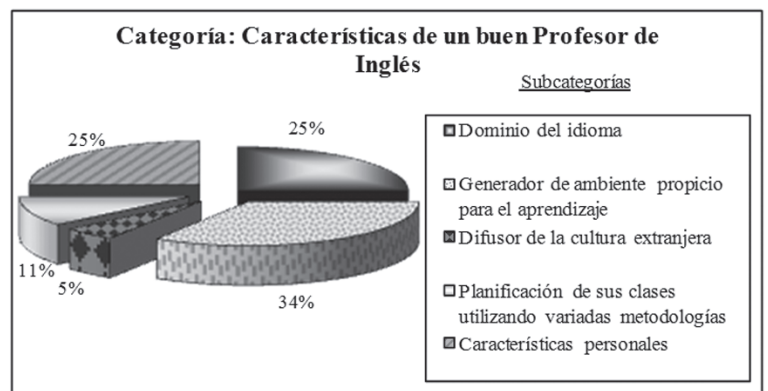

Para indagar acerca del rol que frecuentemente el profesor adopta en el aula, se les solicitó a los informantes que se identificaran con uno o más roles, de un listado propuesto por Brown (2001). La mayor parte se identificó con el rol del profesor como fuente de recursos, rol en el que él o ella adopta un segundo plano para permitir que sus estudiantes procedan con su desarrollo lingüístico, estando siempre disponible para entregar sugerencias cuando el estudiante las busca.

La segunda mayoría se inclinó por el rol de facilitador en donde él o ella facilita el proceso de aprendizaje y ayuda a los estudiantes a superar dificultades y a encontrar sus propios caminos hacia la comunicación. La tercera mayoría manifestó que, dependiendo de la actividad o del tipo de estudiantes, los roles cambian o se entrelazan. Un grupo más reducido opina que su rol es el de planificar las clases para luego permitir a los estudiantes ser creativos dentro de esos parámetros. Finalmente, una pequeña minoría menciona el rol de un profesor controlador que no da muchas posibilidades a los estudiantes para respuestas divergentes. A continuación se pueden apreciar algunos fragmentos de la entrevista semiestructurada seleccionados para respaldar las subcategorías antes mencionadas. 
Tabla 7: Rol del profesor de inglés

\begin{tabular}{|l|l|l|}
\hline Sujeto & Fragmento & $\begin{array}{l}\text { Técnica de gene- } \\
\text { ración de infor- } \\
\text { mación }\end{array}$ \\
\hline 11 & $\begin{array}{l}\text { "Controlador definitivamente } \\
\text { no. Ese es el modelo que } \\
\text { más típicamente se usa en } \\
\text { Chile y tiende a transformar a } \\
\text { los alumnos en que no pien- } \\
\text { san por ellos mismos. Como } \\
\text { directores, yo no estoy de } \\
\text { acuerdo con que se prepare } \\
\text { al coro y que el coro repita. } \\
\text { Es más como manager, per- } \\
\text { mite la creatividad de cada } \\
\text { alumno". }\end{array}$ \\
\hline
\end{tabular}

El siguiente gráfico ilustra las creencias de los profesores respecto a los roles que asumen en el aula.

Gráfico 6: Frecuencia de los roles del profesor de inglés

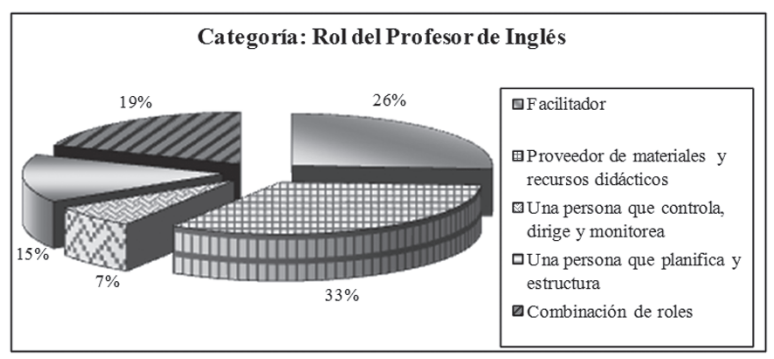

Cuando se les consultó a los profesores si el contexto social de sus estudiantes influía en el proceso de enseñanza y aprendizaje, la respuesta generalizada fue que contribuía en gran medida por distintas razones. Por un lado, porque el contexto social influye en la riqueza cultural de los estudiantes y es considerado como una herramienta importante durante las clases de idioma. Por otro lado, el contexto social determina, en cierta medida, las creencias, las actitudes y las aspiraciones que los estudiantes demuestran y/o declaran. En la siguiente tabla se presentan algunos fragmentos de la entrevista semiestructurada, seleccionados con el fin de ilustrar las subcategorías antes mencionadas.

Tabla 8: Contexto social de los estudiantes

\begin{tabular}{|l|l|l|}
\hline Sujeto & Fragmento & $\begin{array}{l}\text { Técnica de generación } \\
\text { de información }\end{array}$ \\
\hline 15 & $\begin{array}{l}\text { "Es evidente que sí, el acervo } \\
\text { cultural que trae cada estu- } \\
\text { diante...determina los niveles } \\
\text { de logro". }\end{array}$ & $\begin{array}{l}\text { Entrevista semiestruc- } \\
\text { turada }\end{array}$ \\
\hline
\end{tabular}

Para abordar la siguiente categoría, es decir, funciones más frecuentes realizadas por el profesor de inglés, se trabajó con dos fuentes: la entrevista y el diario autobiográfico. Durante la entrevista se le entregó a los profesores un listado con una serie de funciones docentes, cada profesor señaló aquellas que utilizaban con mayor frecuencia. Por otro lado, se analizó el diario autobiográfico para constatar las funciones mayormente realizadas. A través de la entrevista surgen las subcategorías de mayor preferencia: la retroalimentación positiva y el monitoreo del trabajo de los estudiantes. A estas le siguen la respuesta a interrogantes y la demostración de actividades. Las menos mencionadas fueron la enseñanza de estrategias y el manejo de curso. Con referencia a las estrategias, los profesores manifiestan no tener mayor conocimiento de estas por lo que no las utilizan en el proceso de enseñanza y aprendizaje. Respecto al manejo de curso, los profesores plantean que a nivel universitario no se presentan problemas que requieran de esta función. En la siguiente figura se aprecian algunos fragmentos del diario autobiográfico y de la entrevista semiestructurada seleccionados para respaldar las subcategorías antes mencionadas.

Tabla 9: Funciones más frecuentes realizadas por el profesor de inglés

\begin{tabular}{|l|l|l|}
\hline Sujeto & Fragmento & $\begin{array}{l}\text { Técnica de genera- } \\
\text { ción de información }\end{array}$ \\
\hline 4 & $\begin{array}{l}\text { "Como profesor atendí a con- } \\
\text { sultas y monitoreé el trabajo } \\
\text { grupal". }\end{array}$ & Diario autobiográfico \\
\hline 15 & $\begin{array}{l}\text { "Yo ocupo mucho las pregun- } \\
\text { tas dentro de las funciones. } \\
\text { Para mi el preguntar es una } \\
\text { de las tareas docentes vitales. } \\
\text { Creo que la pregunta es una } \\
\text { herramienta que te ayuda no } \\
\text { sólo en la reflexión, sino que la } \\
\text { pregunta es como un espejo, } \\
\text { muchas veces". }\end{array}$ & \\
\hline
\end{tabular}

El siguiente gráfico muestra las funciones más frecuentes realizadas por el profesor de inglés, según lo declarado por los informantes. 
Gráfico 7: Frecuencia de las funciones más frecuentes realizadas por el profesor de inglés

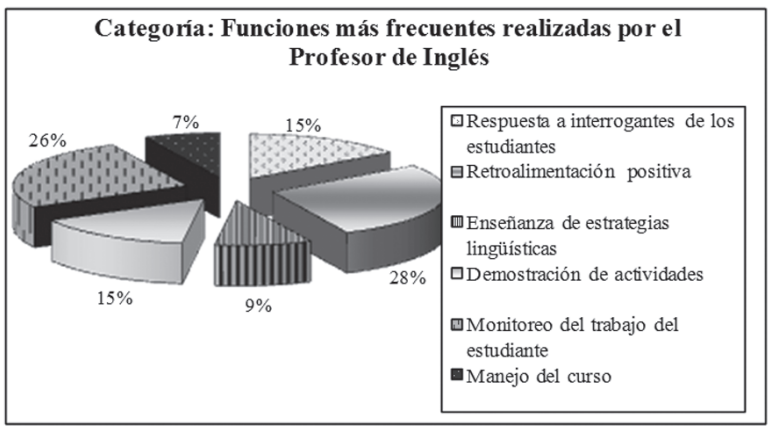

Al momento de ser consultados respecto a la categoría estrategias de aprendizaje promovidas en las clases de inglés, la mayoría de los profesores manifestó no enseñar estrategias de aprendizaje por desconocimiento del concepto o por no distinguir las estrategias adecuadas para trabajar las distintas habilidades. La menor parte de los profesores manifestó enseñar estrategias, no sólo lingüísticas, sino también de aprendizaje. Este grupo declara que para enseñar un idioma es imprescindible no solo conocer las estrategias de aprendizaje y usarlas durante las clases, sino enseñarlas explícitamente a los estudiantes para que puedan aplicarlas en otros contextos. A continuación se aprecian algunos fragmentos de la entrevista semiestructurada seleccionados para ejemplificar estas aseveraciones.

Tabla 10: Estrategias de aprendizaje promovidas en las clases de inglés

\begin{tabular}{|l|l|l|}
\hline Sujeto & Fragmento & $\begin{array}{l}\text { Técnica de gene- } \\
\text { ración de informa- } \\
\text { ción }\end{array}$ \\
\hline 12 & $\begin{array}{l}\text { "Sí, leyendo aquí esto de la ense- } \\
\text { ñanza de estrategias lingüísticas, } \\
\text { yo creo que ahí estoy débil. Creo } \\
\text { que hasta ahora no me he dedi- } \\
\text { cado a tomar ese punto en cómo } \\
\text { hacerlo, cómo empezar". }\end{array}$ & $\begin{array}{l}\text { Entrevista semies- } \\
\text { tructurada. }\end{array}$ \\
\hline
\end{tabular}

A través del siguiente gráfico se observa las estrategias de aprendizaje que los docentes declaran promover.
Gráfico 8: Frecuencia de estrategias de aprendizaje promovidas en las clases de inglés

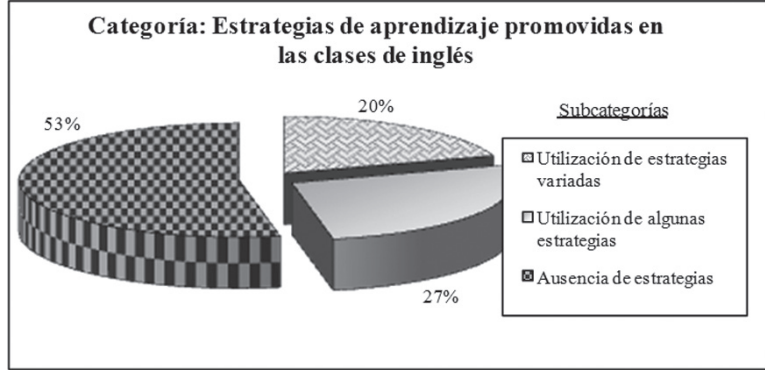

En la categoría características de un profesional de la educación, se mencionaron cuatro subcategorías con una frecuencia similar. La primera es la formación disciplinar y pedagógica del profesor, en donde uno de los rasgos mayormente mencionados es el poseer un buen manejo del idioma inglés. Otra característica es el aprendizaje continuo, tanto en la disciplina como en el ámbito pedagógico, donde el perfeccionamiento, la autonomía y la actualización en distintas áreas adquieren un rol fundamental. Un tercer grupo considera muy relevante mantener un compromiso educativo con los estudiantes. Un número similar de profesores manifiesta la importancia de que un profesor practique la reflexión de su práctica pedagógica; sin embargo, manifestaron no hacerlo con la frecuencia apropiada. Respecto a producir conocimiento, la mayoría planteó la necesidad de una mayor cantidad de investigaciones. Finalmente, la característica menos mencionada es el compromiso con la institución educativa (Ver tabla 11). A continuación se observan algunos fragmentos de las entrevistas semiestructuradas donde los informantes clave mencionan las características de un profesional de la educación.

Tabla 11: Características de un profesional de la educación

\begin{tabular}{|l|l|l|}
\hline Sujeto & Fragmento & $\begin{array}{l}\text { Técnica de generación } \\
\text { de información }\end{array}$ \\
\hline 8 & $\begin{array}{l}\text { "Creo que tengo una buena } \\
\text { formación disciplinaria } \\
\text { pedagógica, cuento con ese } \\
\text { requisito. Estoy continuamente } \\
\text { preocupada de mejorar, } \\
\text { de estudiar y aplicar cosas } \\
\text { nuevas". }\end{array}$ & $\begin{array}{l}\text { Entrevista } \\
\text { semiestructurada }\end{array}$ \\
\hline
\end{tabular}


A través del siguiente gráfico se observan las características que, según los informantes clave, debe poseer un profesional de la educación.

Gráfico 9: Frecuencia de las características de un profesional de la educación

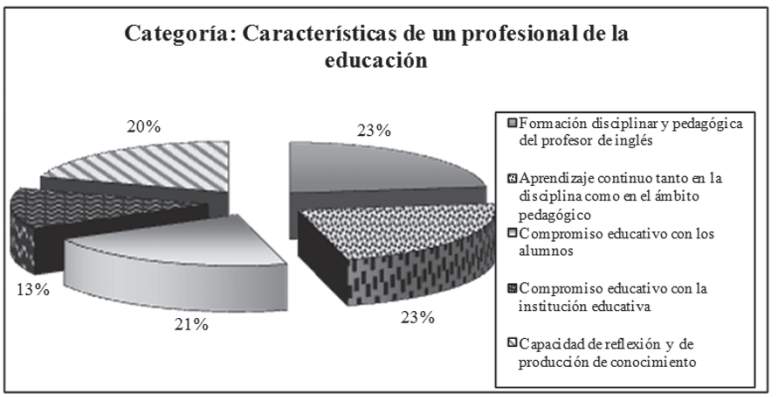

$\mathrm{Al}$ ser consultados respecto a si consideraban necesario realizar cambios en la docencia del inglés en Chile, emerge la categoría cambios sugeridos para los docentes de inglés en Chile. Los docentes mencionaron, en primer lugar, aspectos relacionados con cambios de actitud, tales como: desarrollo de la autocrítica, trabajo en equipo o mayor autonomía. El segundo lugar lo comparten aspectos metodológicos y aspectos administrativos tales como la disminución de la carga académica, el número de estudiantes por sala o el perfeccionamiento dentro de los propios establecimientos. Cabe destacar la baja frecuencia que presenta la sugerencia de cambios a la formación inicial de los docentes. La siguiente tabla contiene fragmentos de la entrevista semiestructurada que ilustran lo anterior.

Tabla 12: Cambios sugeridos para los docentes de inglés en Chile

\begin{tabular}{|l|l|l|}
\hline Sujeto & Fragmento & $\begin{array}{l}\text { Técnica de gene- } \\
\text { ración de infor- } \\
\text { mación }\end{array}$ \\
\hline 7 & $\begin{array}{l}\text { "Aprendizaje continuo tanto } \\
\text { en la disciplina como en el } \\
\text { ámbito pedagógico. Yo creo } \\
\text { que recién ahora los profe- } \\
\text { sores hemos sentido eso de } \\
\text { la necesidad de seguir apren- } \\
\text { diendo". }\end{array}$ & $\begin{array}{l}\text { Entrevista se- } \\
\text { miestructurada }\end{array}$ \\
\hline
\end{tabular}

El siguiente gráfico ilustra los cambios sugeridos en la docencia de inglés en Chile.
Gráfico 10: Cambios sugeridos para docentes de inglés en Chile

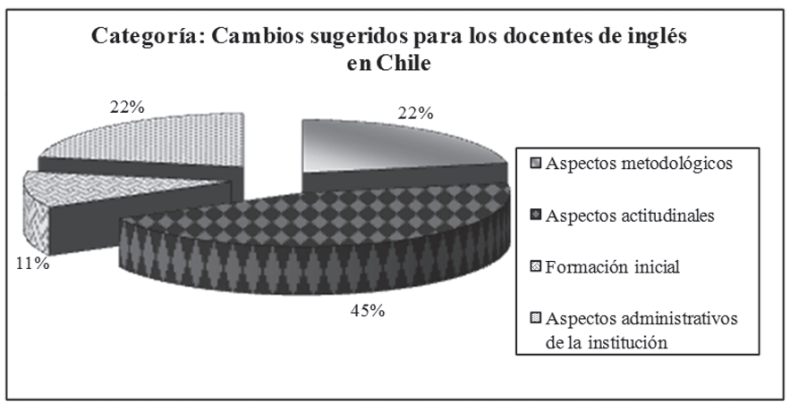

Con respecto al tipo de perfeccionamiento sugerido para los docentes de inglés en Chile, se manifiesta primordialmente la necesidad de actualización en nuevas metodologías de enseñanza de idiomas, TIC, estilos de aprendizaje, estrategias de aprendizaje, capacidad de reflexión y evaluación de proceso. En segundo lugar, se encuentra el mejoramiento del manejo del idioma y de la gestión de aula. Por último, en la subcategoría áreas de interés, se mencionan las neurociencias (conjunto de ciencias cuyo objeto de investigación es el sistema nervioso, con particular interés en cómo la actividad del cerebro se relaciona con la conducta y el aprendizaje) y las pasantías, definidas como un conjunto de actividades de carácter práctico realizadas por el profesional de la educación, que le permitirán la aplicación en forma integrada y selectiva de conocimientos, habilidades, destrezas, aptitudes y valores en casos concretos del campo educacional. Además se mencionan algunas áreas específicas relacionadas con la enseñanza y aprendizaje del inglés.

Tabla 13: Tipo de perfeccionamiento sugerido

\begin{tabular}{|l|l|l|}
\hline Sujeto & Fragmento & $\begin{array}{l}\text { Técnica de genera- } \\
\text { ción de información }\end{array}$ \\
\hline 4 & $\begin{array}{l}\text { "Creo que necesitamos } \\
\text { un bagaje de lo que son } \\
\text { los estilos de aprendizaje } \\
\text { con las estrategias de } \\
\text { aprendizaje, en el sentido } \\
\text { que entendamos que no } \\
\text { todos los alumnos van } \\
\text { a aprender de la misma } \\
\text { manera". }\end{array}$ \\
\hline
\end{tabular}

El siguiente gráfico ilustra el tipo de perfeccionamiento sugerido. 
Gráfico 11: Frecuencia de tipo de perfeccionamiento sugerido

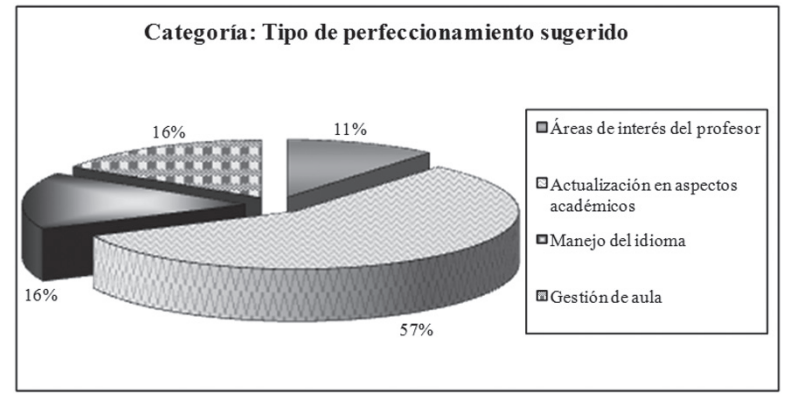

Dentro de los aspectos más reconfortantes de ser profesor, la mayor parte apuntó a la satisfacción que les producía comprobar que sus estudiantes aprendían y lograban los objetivos propuestos. Un segundo aspecto es la posibilidad de contactarse con los estudiantes en un plano más personal y de establecer relaciones con ellos. Parece interesante notar la importancia otorgada a lograr cambios en los estudiantes, no siempre asociados al aprendizaje del idioma (Ver tabla 14).

Tabla 14: Aspectos reconfortantes de ser profesor

\begin{tabular}{|l|l|l|}
\hline Sujeto & Fragmento & $\begin{array}{l}\text { Técnica de } \\
\text { generación de } \\
\text { información }\end{array}$ \\
\hline 8 & $\begin{array}{l}\text { "Yo creo que lo más reconfortante } \\
\text { es ver como tus alumnos cambian su } \\
\text { vida, verlos transformarse en otras } \\
\text { personas felices, en profesionales exi- } \\
\text { tosos con buenos trabajos". }\end{array}$ & $\begin{array}{l}\text { Entrevista } \\
\text { semiestructu- } \\
\text { rada }\end{array}$ \\
\hline
\end{tabular}

El siguiente gráfico ilustra los aspectos reconfortantes de ser profesor.

Gráfico 12: Frecuencia de los aspectos reconfortantes de ser profesor

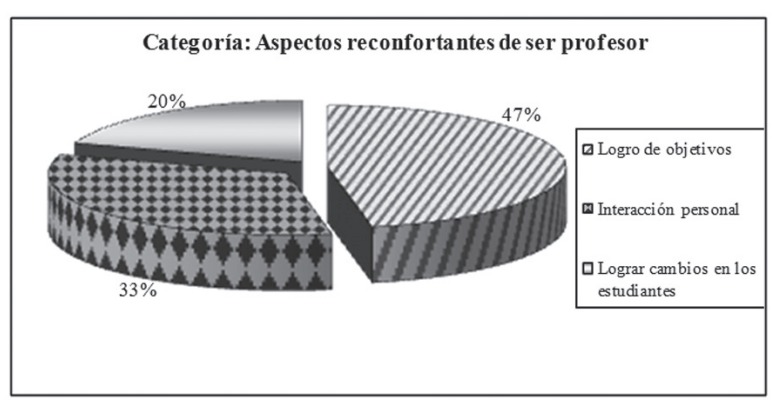

$\mathrm{Al}$ indagar respecto a los aspectos menos reconfortantes de ser profesor, se puede observar que, en primer lugar, se encuentra la falta de motivación de los estudiantes por aprender. Esto se ve reflejado en un excesivo interés por aprobar asignaturas, la no realización de trabajos, la falta de rigurosidad o la escasa participación durante las clases. Por otro lado, los profesores manifiestan sentirse frustrados cuando sus estudiantes no logran los objetivos propuestos. Finalmente, se mencionan algunos aspectos administrativos, tales como bajo sueldo, carga horaria o trabajo administrativo (Ver tabla 15). El siguiente cuadro contiene fragmentos de la entrevista semiestructurada que ilustran lo anterior.

Tabla 15: Aspectos menos reconfortantes de ser profesor

\begin{tabular}{|l|l|l|}
\hline Sujeto & Fragmento & $\begin{array}{l}\text { Técnica de } \\
\text { generación de } \\
\text { información }\end{array}$ \\
\hline 11 & $\begin{array}{l}\text { "Hubo periodos de silencio absoluto } \\
\text { que produjeron mucha frustración por } \\
\text { parte mía e incomodidad por parte de } \\
\text { los alumnos". }\end{array}$ & $\begin{array}{l}\text { Diario auto- } \\
\text { biográfico }\end{array}$ \\
\hline 8 & $\begin{array}{l}\text { Sentir que lo que uno hace no tiene ni } \\
\text { un efecto o no tiene ni un impacto en } \\
\text { la vida de los alumnos". }\end{array}$ & $\begin{array}{l}\text { Entrevista } \\
\text { semiestructu- } \\
\text { rada }\end{array}$ \\
\hline 1 & $\begin{array}{l}\text { "Los momentos menos reconfortan- } \\
\text { tes ocurren cuando ves alumnos frus- } \\
\text { trados, repitiendo y no avanzando". }\end{array}$ & $\begin{array}{l}\text { Entrevista } \\
\text { semiestructu- } \\
\text { rada }\end{array}$ \\
\hline
\end{tabular}

El siguiente gráfico sintetiza los aspectos menos reconfortantes de ser profesor.

Gráfico 13: Frecuencia de aspectos menos reconfortantes de ser profesor

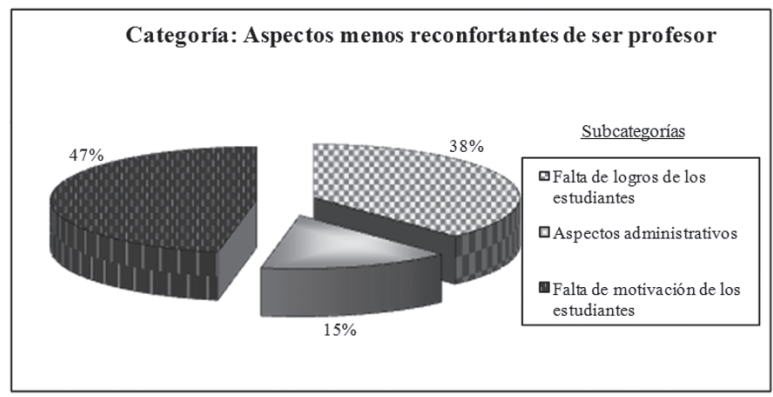

En cuanto a la evaluación docente, la totalidad de los profesores se declaran totalmente partidarios de esta. En la próxima categoría, sugerencia de formato de evaluación docente, la mayor parte de los profesores sugieren la observación directa en el aula debido a que esta permite percibir de manera inmediata y fidedigna los diversos fenómenos que ocurren dentro de la sala de clases. La segunda mayoría señaló la importancia de que la evaluación 
docente se lleve a cabo por un especialista del área, por un profesional que pueda aportar concretamente a la superación de aquellas áreas que se observen débiles. Un tercer grupo sugiere que la evaluación docente debiera tener en cuenta la participación de distintos agentes del ámbito educativo, tales como: coordinadores de área, profesionales pares y/o estudiantes que evalúen las competencias del docente (Ver tabla 16). La siguiente tabla contiene algunos fragmentos de la entrevista semiestructurada donde se proponen distintas sugerencias.

Tabla 16: Sugerencia de formato de evaluación docente

\begin{tabular}{|l|l|l|}
\hline Sujeto & Fragmento & $\begin{array}{l}\text { Técnica de } \\
\text { generación de } \\
\text { información }\end{array}$ \\
\hline 3 & $\begin{array}{l}\text { "En cualquier tipo de } \\
\text { trabajo uno debiera } \\
\text { estar siendo evaluado } \\
\text { constantemente a través } \\
\text { de la observación directa, } \\
\text { no avisada, continua... } \\
\text { por una persona realmente } \\
\text { capacitada para hacerlo, } \\
\text { por una persona que tenga } \\
\text { más experiencia que tú, } \\
\text { académica y con mayor } \\
\text { perfeccionamiento". }\end{array}$ & \\
\hline
\end{tabular}

El siguiente gráfico sintetiza las sugerencias de formato para la evaluación docente.

Gráfico 14: Frecuencia de sugerencia de formato de evaluación docente

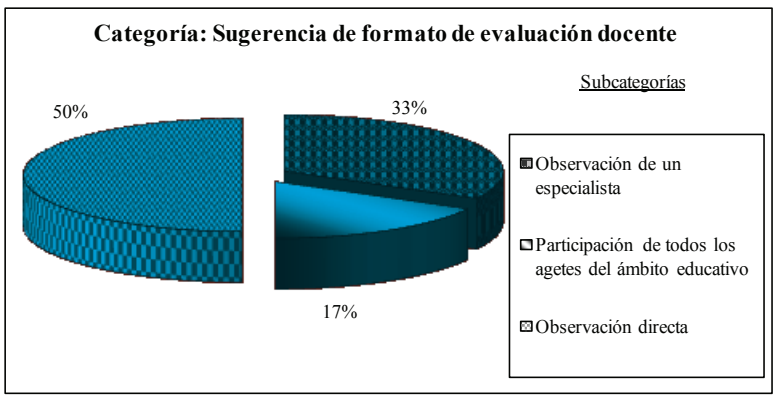

\section{Consideraciones finales}

La investigación acerca de las creencias lingüísticopedagógicas de los profesores cobra importancia, ya que existen antecedentes teóricos y empíricos respecto a cómo estas condicionan su práctica docente. El presente estudio indagó en la dimensión cognitiva de un grupo de 30 profesores de inglés universitarios. La cantidad de informantes clave nos permitió tener una mirada relativamente amplia y profunda de lo que los profesores piensan, saben $y$ creen respecto a lo que hacen en el aula y en el proceso didáctico en general.

Parece interesante recalcar que los docentes expresaron sin dificultad sus creencias lingüísticopedagógicas respecto a los distintos aspectos planteados y reconocieron que estas creencias se generan principalmente desde la teoría o desde su propia experiencia profesional.

Para la mayoría de los informantes, las principales fuentes de formación profesional son la literatura especializada y la experiencia laboral. Dentro de las razones se indica que esta última permite el contacto directo con la realidad y con todos los agentes involucrados en el proceso. Es interesante notar el menor grado de importancia otorgado al perfeccionamiento y a los estudios de pregrado. Una de las razones que explicaría este fenómeno es que el perfeccionamiento se considera poco ajustado a la realidad chilena o distante de las necesidades reales de los profesores. En cuanto a la poca importancia que se le asigna a los estudios de pregrado como fuente de formación profesional, podría deberse a que ello consideraban principalmente aspectos teóricos de la formación disciplinar, donde los profesores manifiestan sentirse conformes con la preparación recibida. Sin embargo, la mayoría expresa disconformidad con la escasa formación práctica otorgada durante sus estudios de pregrado, lo que repercutió especialmente al comienzo de su ejercicio docente. Esto se relaciona en gran medida con el tipo de currículum que conformaba la formación inicial de la mayoría de los profesores informantes, ya que en ese período la práctica docente solo se efectuaba durante el último semestre de estudio, lo que no permitía la posibilidad de tener contacto con situaciones reales en al aula.

Al ser consultados respecto a cómo percibían su forma de enseñar, los profesores la asocian con aspectos tales como la constancia, la adaptación, las altas expectativas o la autonomía. No obstante, la mayor parte de ellos citó la importancia de mantener una relación cercana con los estudiantes, escucharlos 
y tener en cuenta sus necesidades e intereses. Esto podría representar la creencia de que el mantener una relación próxima con los estudiantes no solo contribuye sino que facilita el proceso de enseñanza y aprendizaje.

Respecto a la importancia otorgada por los docentes al contexto social de sus estudiantes, se aprecia que este contribuye en gran medida al proceso de enseñanza y aprendizaje. Algunos de los argumentos que apoyan esta afirmación indican que la riqueza cultural que los estudiantes puedan poseer es una herramienta importante durante las clases de idioma.

Es interesante destacar las características que para los informantes posee un buen profesor de inglés. Todas ellas aluden a rasgos que propicien un ambiente apropiado y facilitador del aprendizaje; además, destacan la importancia de sentirse seguros del dominio del idioma que se está ensañando y de planificar las clases de acuerdo a metodologías innovadoras. En este mismo sentido, la mayoría se identificó con el rol de profesor como fuente de recursos, quien está siempre disponible para consultas o para entregar sugerencias, además de permitir al estudiante que sea protagonista de su desarrollo lingüístico.

Respecto a las funciones más frecuentes realizadas por el docente dentro del aula, se mencionan la retroalimentación positiva y el monitoreo continuo. Parece relevante notar que la gran mayoría de los docentes declara no trabajar estrategias de aprendizaje con sus estudiantes; sin embargo, reconoce su importancia y declara su deseo de ponerlo en práctica. En cuanto al rol del estudiante, la totalidad de los docentes declara que sus alumnos asumen un rol activo, autónomo y participativo durante las clases. Además señalan ciertos aspectos actitudinales de un docente exitoso, tales como la responsabilidad, el esfuerzo y la autonomía.

Todos los docentes reconocen la importancia de tener claros los objetivos pedagógicos dentro del proceso de enseñanza y aprendizaje; no obstante, solo la mitad de ellos declara comunicarlos a los estudiantes, principalmente por la escasez de tiempo en el aula o porque no lo consideran relevante. Respecto a la elección de los contenidos que enseñan, los docentes se guían principalmente por el programa de cada curso, aunque la mayoría reconoce que luego lo adapta a su grupo de estudiantes.

La forma de organización del aula preferida por los docentes es en semicírculo, ya que esta distribución facilita la comunicación. Dentro del ámbito de las interacciones, los docentes señalan utilizar preferentemente el trabajo en pares o una combinación de interacciones, dependiendo de la actividad. El trabajo en grupo es menos frecuente, debido a que los docentes estiman que los estudiantes distraen su atención y tienden a perder el foco de estudio.

Al indagar acerca de las etapas de una clase, la mayoría de los docentes reconoce tres etapas: un primer momento de motivación, un segundo momento de presentación de los contenidos y un tercer momento de práctica de lo presentado, con énfasis en la expresión oral. Entre las actividades más utilizadas figuran la discusión, los debates y el trabajo con ilustraciones. Cabe destacar que los docentes concuerdan en que las actividades relacionadas con las experiencias de los estudiantes resultan altamente exitosas. Con respecto a los materiales o recursos más utilizados, se mencionan las TIC y el material escrito, como hojas de trabajo o guías de aprendizaje. Por otro lado, gran parte de los docentes declaran utilizar los textos guías, donde lo primordial, según su opinión, es que contengan una secuencia y objetivos claros.

Finalmente, el develar las creencias lingüísticopedagógicas de un grupo de docentes universitarios, contribuye con valiosa información a la constante preocupación por diseñar instancias de perfeccionamiento docente que respondan a las necesidades e intereses de los docentes de tal forma que les resulte significativo y de este modo contribuya al mejoramiento de su práctica docente y al logro de aprendizajes de calidad por parte de los estudiantes. Resulta relevante resaltar que la información contenida en este estudio puede favorecer notoriamente a las instituciones formadoras de docentes, otorgándoles una guía desde las creencias de los profesores universitarios con experiencia en formación docente. 


\section{Referencias}

Blazquez, F. y Tagle, T. (2010). Formación docente: un estudio de las creencias de alumnos y profesores sobre el proceso de enseñanza y aprendizaje del inglés. Madrid: Teseo.

Bisquerra, R. (2009). Metodología de la investigación educativa. Madrid: La Muralla.

Borg, S. (2003). Teacher cognition in language teaching: a review of research on what language teachers think, know, believe, and do. The International Abstracting Journal for Language Teachers and Applied Linguists, 36, 81-109.

Brown, D. (2001). Teaching by principles. An interactive approach to language pedagogy. New York: Longman.

Burns, A. \& Richards, J. (2009). The Cambridge guide to second language teacher education. Cambridge: Cambridge University Press.

Canales, M. (2006). Metodologías de investigación social. Introducción a los oficios. Santiago de Chile: LOM.

Cerda, H. (2007). La investigación formativa en el aula. La pedagogía como investigación. Bogota: Investigar. Magisterio.

Corbetta, P. (2007). Metodología y técnicas de investigación social. Madrid. McGraw Hill.

Díaz, C., Martínez, P., Roa, I. y Sanhueza, M. (2010). Una fotografía de las cogniciones de un grupo de docentes de inglés de secundaria acerca de la enseñanza y aprendizaje del idioma en establecimientos educacionales públicos de Chile. Revista Folios ( $\mathrm{N}^{\circ} 31$ ), 69-80. Bogotá: Universidad Pedagógica Nacional.

Freeman, D. (2002). The hidden side of the work: teacher knowledge and learning to teach. A perspective from North American educational research on teacher education in English language teaching. Language Teaching. The International Abstracting Journal for Language Teachers and Applied Linguists, 35, 1-13.

González, S., Río, E. y Rosales, S. (2001). El Currículum oculto en la escuela. Buenos Aires: Lumen Humanitas.

Goodson, I. \& Numan, U. (2002). Teacher's life worlds, agency and policy contexts. Teachers and Thinking: Theory and Practice, Vol. 8 ( $\mathrm{N}^{\circ}$ 5), 57-69.

Kane, R., Sanretto, S. \& Heath, C. (2002). Telling half the story: A critical review of research on the teaching beliefs and practices of university academics. Review of Educational Research, Vol.72 ( $\left.{ }^{\circ} 2\right), 177-228$.
Levin, B. (2001). Lives of teachers: Update on a longitudinal case study. Teacher Education Quarterly, V. 7 ( $\left.\mathrm{N}^{\circ} 34\right), 29-47$.

Levin, B. \& He, Y. (2008). Investigating the content and sources of teacher candidates' personal practical theories (PPTS). Journal of Teacher Education, Vol. 59 (1), 55-68. January/February 2008.

Montecinos, C., Solís, M., Contreras, I. y Rittershaussen, S. (2009). Muestras de desempeño docente. Instrumento para evaluar la calidad de la enseñanza y su impacto en el aprendizaje. Santiago de Chile: Ediciones UC.

Pintor, M. y Vizcarro, C. (2005). Cómo aprenden los profesores, un estudio empírico basado en entrevistas. Revista Complutense de Educación, Vol.16 (2), 623-644.

Sandín, M. (2003). Investigación cualitativa en educación. Fundamentos y tradiciones. Madrid: Mc Graw Hill.

Sevillano, M., Pascual, M. Y Bartolomé, D. (2007). Investigar para innovar la enseñanza. Madrid: Pearson. Prentice Hall.

Stenberg, K. (2011). Working with identities-promoting student teachers'professional development. Helsinki: Department of Teacher Education.

Tsui, A. (2003). Understanding expertise in teaching. Cambridge: Cambridge University Press.

Tudor, I. (2001). The dynamics of the language classroom. Cambridge: Cambridge University Press.

Wilkinson, D. \& Birmingham, P. (2003). Using research instruments. A guide for researchers. New Cork: Routledge Farmer. 